\title{
Robust Fuzzy Control for Doubly Fed Wind Power Systems with Variable Speed Based on Variable Structure Control Technique
}

\author{
Xizheng Zhang ${ }^{1,2}$ and Yaonan Wang ${ }^{1}$ \\ ${ }^{1}$ School of Electrical \& Information Engineering, Hunan University, Changsha 410082, China \\ ${ }^{2}$ The CIC of Wind Power Equipment and Energy Conversion, Hunan Institute of Engineering, Xiangtan 411104, China \\ Correspondence should be addressed to Xizheng Zhang; z_x_z2000@163.com
}

Received 5 July 2014; Revised 28 October 2014; Accepted 28 October 2014; Published 18 November 2014

Academic Editor: Linni Jian

Copyright (c) $2014 \mathrm{X}$. Zhang and Y. Wang. This is an open access article distributed under the Creative Commons Attribution License, which permits unrestricted use, distribution, and reproduction in any medium, provided the original work is properly cited.

\begin{abstract}
The design of a variable structure sliding-mode controller (SMC) for a variable speed wind turbine with double-fed inductiongenerator, based on the fuzzy logic, is described in this paper. The purpose of this controller is to maximize the energy capture by operating the turbine at the optimal rotational speed as well as fast and stable generator response. The dynamics of both the turbine and the generator are modeled to exhibit their mechanical/electrical characteristics. Two global sliding-mode controllers, which eliminate the reaching phase of SMC and the sliding-mode motion starts from the beginning, are designed to guarantee the robust tracking of both the optimal blade-rotor speed and the reference generator torque/flux in the whole process, despite the parametric uncertainty and external disturbance. To reduce the adverse chattering effect of the conventional SMC, the adaptive fuzzy inference strategy is adopted to deduce the adjustable switch gain, instead of the fixed gains. Simulation results show that the proposed controller achieves global asymptotic tracking, satisfied torque/flux responses, and has better performance and higher utilization ratio of wind energy than the conventional feedback-linearization method.
\end{abstract}

\section{Introduction}

In recent years, the development of wind power generation technology is rapid, and its installed capacity and market share continuously increase. It is reported that the global wind power installed capacity reaches 282 million kilowatts (GW) in 2012 and $318 \mathrm{GW}$ in 2013. The Global Wind Energy Council will release the annual growth rate over the next five years (2014-2018) of the global wind power development forecast in April 2014, but GWEC expects newly installed capacity in 2014 will return to levels even more than in 2012 $[1,2]$. In 2013, China added $16.1 \mathrm{GW}$ of wind power capacity and the cumulative capacity exceeded $90 \mathrm{GW}$. Wind power was continuing to occupy the third largest position leading to the nuclear power, and its average utilization hours exceed over 2,000 hours for the first time, with an increase of 100 hours more than in the year 2012 [3].

With the further study and application of wind turbines, the importance of the control technology for improving its performance has been gradually recognized by researchers, so it is very significant to have a deep further study on the modeling and control of the wind turbine generator $[4,5]$. Among various wind power systems, the doubly fed induction generator system with variable speed and constant frequency (VSCF) is a competitive one due to its advantages such as high energy efficiency, controllable power factor, and small capacity of converter [6-8]. The control objective of the VSCF-based wind power system is to minimize the operating power within the scope of available wind speed. In other words, the operating efficiency of generator can be improved by adjusting its exciting voltage to alter its running speed, which can indirectly adjust the rotational speed of the wind turbine $[9,10]$. Therefore, the tip speed ratio can reach the optimal value, and the maximum wind energy can be captured. The complexity of its control was mainly due to the randomness of wind and the strong nonlinearity of wind power system, the DFIG as a multiple-input multiple-output system, the existence of uncertainty of model parameters, the external disturbances, and the fluctuating grid voltage, and so forth [11, 12]. 
For conventional control techniques, most of the designs only make use of the linearized model around the operating point of the system. As reported in [13], the DFIG was linearly separated into two one-order linear subsystems (active power and reactive power) based on the inverse system method. Under steady-state situation, several nonlinear controllers were developed in the work of [14], but the dynamic features of wind and wind turbine were not considered. Moreover, the performance of these nonlinear controllers relies on the invariance of the parameters.

The proportional-integral-derivative (PID) controller and several modified PID schemes have been widely developed to design the industrial control systems including wind turbines [15-17]. Although PID-based schemes are believed to be the easiest and simplest designing method, these kinds of schemes always lack a general effective tuning principle of the control coefficients $\left(k_{p}, k_{i}\right.$, and $\left.k_{d}\right)$ and are difficult to determine their stability regions. In the work of [17], an optimal PID controller based on PSO-RBFNN is developed for wind turbine systems; however, the training algorithm and the optimization routine are complex enough, which definitely imposes unwelcoming computation burden on the controller design.

In the work of [18], a robust nonlinear controller based on adaptive backstepping technique is developed for the variable speed control of wind turbines. This method achieves globally asymptotic speed tracking despite the parametric uncertainty on mechanical/electrical subsystems. However, the main shortcomings are that this method assumes the integral of the reference states to be bounded and cannot provide the global stability at the whole operation regions.

The variable structure sliding mode (VSSM) is a control technique which has strong robustness for the parameter perturbations and external disturbances, and it exhibits a good control effect for the applications in the nonlinear system [19-21]. There are two main shortcomings when conventional VSSM is applied into practice, the noise sensitive during the sliding-mode reaching stage and the chattering phenomena. In the work of [20], a nonlinear controller based on feedback linearization theory for converter-based wind turbines is developed to limit the converter currents within the designed ranges at grid faults. To reduce the implementation complexity, the equivalent control concept of sliding mode approach is adopted to design the control law. However, this design ignores the generator dynamics and the chattering reduction in sliding motion just depends on a low pass filter, which results in the inaccurate modeling and control performance degradation. In the work of [21], the problem of controlling power generation in variable-speed wind turbines is dealt with based on VSSM control strategy. However, this design does not consider the electromagnetic dynamics and has not presented the flux and electromagnetic torque control approach.

The solution to first problem in this paper is proposed by utilizing global sliding mode control (GSMC) instead of conventional SMC [22]. By doing this, this scheme can eliminate the reaching phase of sliding mode control, and the sliding-mode motion starts from the beginning. Thus, the system has a strong robustness in the whole process.
In order to overcome the undesired effect of uncertainty and external disturbances, a high switch control gain is usually used in those VSSM controllers. However, the obtained control effort exhibits a strong chattering which can cause the instability operating, machinery wearing, energy loss, and low efficiency of the wind turbines. As well known, fuzzy logic control (FLC) is a knowledge-based control approach which can mimic human experience in controlling complex systems and has excellent capability to deal with nonlinear plants [23-25]. This method is a good choice for inferring the control gains of VSSM controller in wind turbines through fuzzy-rules-based inference. Meanwhile, the modeling error and the uncertain disturbance of wind power system can be estimated to obtain the appropriate switch gain through a fuzzy inference system with single input and single output.

Some researches on the combination of FLC and SMC have been done into the application of wind energy conversion system, such as in [26-30]. A fuzzy sliding mode-based power control design is proposed for wind turbine in [26, 27], where FLC is applied to approximate the discontinuous switching control term, thus the nature merit of SMC has also vanished as well as the chattering. The FLC is used to optimize the reference generator speed for maximum power tracking in [28], while no term of the SMC controller needs FLC. In $[29,30]$, the fuzzy-logic inference system with two inputs, the rotor tracking error and its derivative, is utilized to determine the switch gains of SMC, while the control object is just the active power and the reactive power without considering speed/torque tracking. Moreover, the existing schemes adopt either the linear switch surface on current error or the integral switch surface on the pitch angle, and none of them adopts the global sliding surface to ensure the global sliding-mode motion in the whole process.

Motivated by the above discussion, this work combines global sliding-mode control and fuzzy control techniques together, and the fuzzy logic was adopted to adaptively adjust the switch grain of sliding mode to soften the torque control and to relieve or avoid the chattering in the conventional SMC control. To the best of our knowledge, it is the first time to apply the fuzzy global sliding mode control into wind turbine controller design. The rest of the paper is organized as follows. Section 2 is dedicated to present the modeling framework of the considered doubly fed wind power system. This model is used for the sliding surfaces and control laws design for DFIG and wind turbine, as detailed in Sections 3 and 4 , respectively. Section 5 focuses on the fuzzy inference system design. Finally, Section 6 presents several simulation results and conclusion and future work are grouped together in Section 7.

\section{Control Model of the Wind Power Generation System}

The wind power generation system can be divided into two subsystems as the wind turbine and the DFIG. The mathematical models of these two subsystems were established as well as the control objective and the control system structure. 


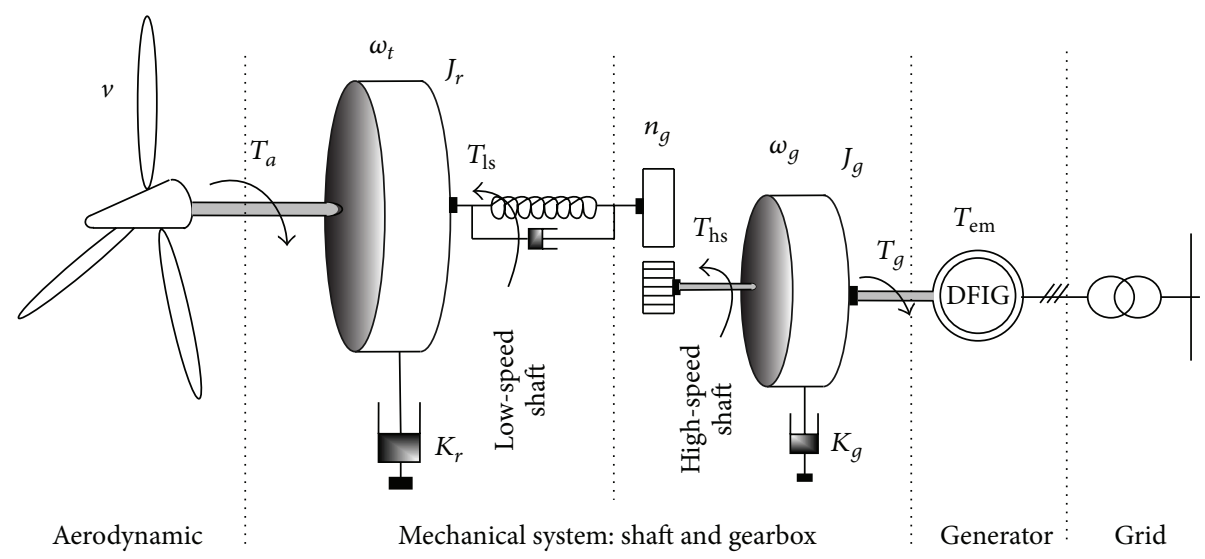

FIGURE 1: Driving structure of the wind turbine.

2.1. Model of the Wind Turbine. Under the wind speed $v$ $(\mathrm{m} / \mathrm{s})$, the wind energy and the torque captured by the fixedpitch variable speed wind turbine can be expressed as follows [10]:

$$
\begin{aligned}
& P_{a}=\frac{1}{2} \rho \pi R^{2} C_{p}(\lambda, \beta) v^{3}, \\
& T_{a}=\frac{1}{2} \rho \pi R^{3} C_{q}(\lambda, \beta) v^{2} .
\end{aligned}
$$

In (1), the notations $\rho, R, \beta$, and $\omega_{t}$, respectively, represent the air density, the bland radius, the pitch angle, and the rotating speed of blade. The tip speed ratio is $\lambda=\omega_{t} R / v . C_{p}(\lambda, \beta)$ and $C_{q}(\lambda, \beta)$ are, respectively, the power coefficient and the torque coefficient. The $C_{p}(\lambda, \beta)$ has the maximum value of $C_{p \text {,opt }}$ at the specific point $\left(\lambda_{\text {opt }}, \beta_{\text {opt }}\right)$. In order to keep the tip speed ratio at the optimal value of $\beta_{\text {opt }}$, for a given wind speed $(v)$, the blade speed $\omega_{t}$ should simultaneously increase or decrease with $v$. In other words, it is necessary to adjust the generator torque to follow the optimal blade speed $\left(\omega_{\text {to }}=\lambda_{\text {opt }} v / R\right)$.

In Figure 1, it shows the driving structure of the wind turbine subsystem. The blade is driven by the wind torque $\left(T_{a}\right)$ and runs with the speed of $\omega_{t}$, and the speed is increased to $\omega_{g}=n_{g} \omega_{t}$ through a transfer case, where $n_{g}$ denotes the gear ratio. The low-speed input and high-speed output torques are $T_{\mathrm{ls}}$ and $T_{\mathrm{hs}}$, respectively. After overcoming the electromagnetic torque $\left(T_{\mathrm{em}}\right)$, the $T_{\mathrm{hs}}$ will drive the generator to run at the speed of $\omega_{g}$ in the power generation mode.

Figure 2 shows the power coefficient $C_{p}(\lambda, \beta)$, the torque coefficient $C_{q}(\lambda, \beta)$ of the wind turbine as functions of the tip speed ration $(\lambda)$ for different pitch angles $(\beta)$, which ranged from 0 to 30 degrees. It shows that, for $\beta=0$, the optimum tip speed ration is $\lambda_{\text {opt }}=10$ for the power coefficient $\left(C_{p \text {,opt }}=\right.$ $0.44)$ and $\lambda_{\text {opt }}=7.5$ for the torque coefficient $\left(C_{q, \mathrm{opt}}=\right.$ 0.05 ), but for a larger pitch angle the value of $\lambda_{\text {opt }}$ decreases correspondingly.

Assuming the low-speed shaft of the wind turbine is ideally rigid, the motion equation of the whole transmission parts can be expressed as follows:

$$
J_{t} \dot{\omega}_{t}=T_{a}-K_{t} \omega_{t}-T_{g}
$$

where $J_{t}=J_{r}+n_{g}^{2} J_{g}, K_{t}=K_{r}+n_{g}^{2} K_{g}$, and $T_{g}=n_{g} T_{\mathrm{em}}$ represent the whole system inertia, the external friction coefficient, and the generator torque, respectively.

2.2. Model of the DFIG Generator. It was assumed that the stator, rotor, and three-phase winding of the DFIG were symmetrically and uniformly distributed, the air gap is uniform, and the electrical/magnetic circuits are also symmetrically distributed. The losses of the hysteresis and eddy-current were neglected, and only the fundamental components of the stator/rotor currents were considered. In the $d$-q coordinates of the stator, the state equation of the DFIG as a function of the stator current and the rotor flux linkage can be expressed as follows [31]:

$$
\begin{aligned}
& \dot{\mathbf{x}}=f(\mathbf{x})+\mathbf{g}_{r} \mathbf{u}_{r}+\mathbf{g}_{s} \mathbf{u}_{s}+\mathbf{d} T_{\mathrm{hs}}, \\
& \mathbf{y}=h(\mathbf{x}),
\end{aligned}
$$

where $\mathbf{x}=\left(\omega_{g}, i_{s d}, i_{s q}, \lambda_{r d}, \lambda_{r q}\right)^{T}, \mathbf{i}_{s}=\left(i_{s d}, i_{s q}\right)^{T}, \mathbf{u}_{s}=$ $\left(u_{s d}, u_{s q}\right)^{T}, \lambda_{r}=\left(\lambda_{r d}, \lambda_{r q}\right)^{T}$, and $\mathbf{u}_{r}=\left(u_{r d}, u_{r q}\right)^{T}$ represent the state variable, the stator current, the stator voltage, the flux linkage of rotor, and the rotor voltage, respectively. $T_{\mathrm{hs}}=$ $T_{a} / n_{g}$, and the nonlinear functions in (3) can be expressed as follows:

$$
\begin{aligned}
& f(\mathbf{x})=\left(\begin{array}{l}
f_{1}(x) \\
f_{2}(x) \\
f_{3}(x) \\
f_{4}(x) \\
f_{5}(x)
\end{array}\right) \\
&=\left(\begin{array}{c}
a_{1} x_{1}+a_{2}\left(x_{3} x_{4}-x_{2} x_{5}\right) \\
a_{3} x_{2}+a_{4} x_{4}+a_{5} x_{1} x_{5} \\
a_{3} x_{3}+a_{4} x_{5}-a_{5} x_{1} x_{4} \\
a_{6} x_{2}+a_{7} x_{4}+a_{8} x_{1} x_{5} \\
a_{6} x_{3}+a_{7} x_{5}-a_{8} x_{1} x_{4}
\end{array}\right), \\
& \mathbf{g}_{r}=\left(\begin{array}{cc}
0 & 0 \\
b_{1} & 0 \\
0 & b_{1} \\
1 & 0 \\
0 & 1
\end{array}\right),
\end{aligned}
$$




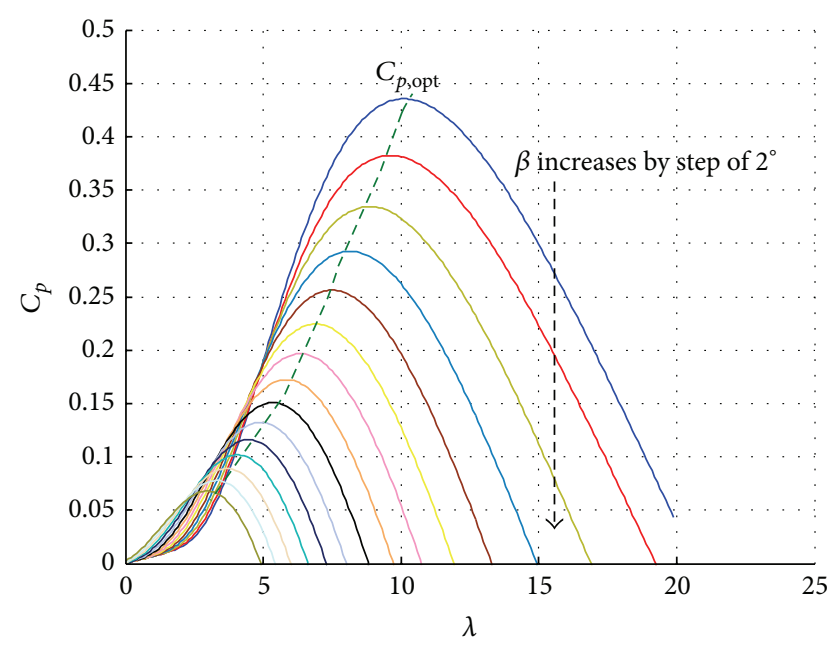

(a)

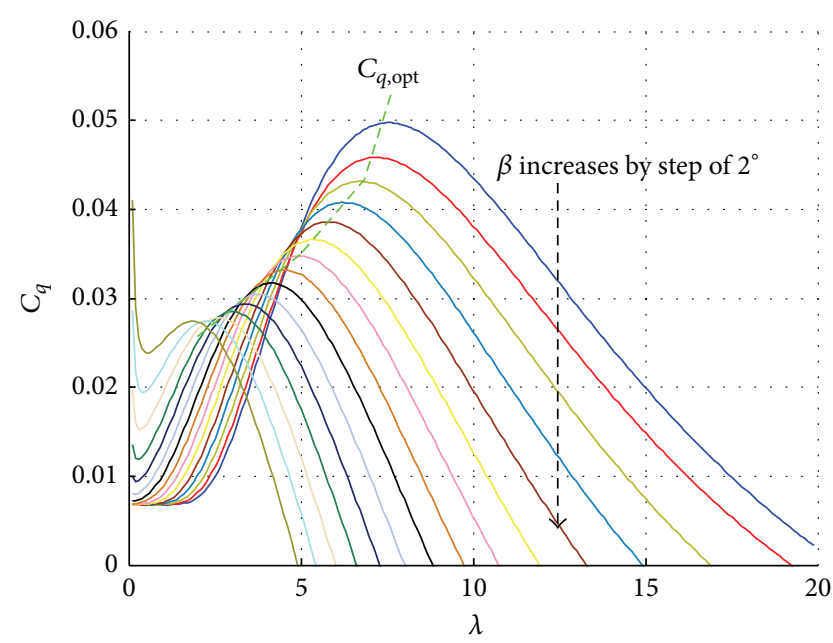

(b)

Figure 2: Turbine power and torque characteristics. (a) Power coefficient $C_{p}(\lambda, \beta)$; (b) torque coefficient $C_{q}(\lambda, \beta)$.

$$
\begin{gathered}
\mathbf{g}_{s}=\left(\begin{array}{cc}
0 & 0 \\
b_{2} & 0 \\
0 & b_{2} \\
0 & 0 \\
0 & 0
\end{array}\right), \\
\mathbf{d}=\left(\begin{array}{c}
b_{3} \\
0 \\
0 \\
0 \\
0
\end{array}\right), \\
a_{1}=\frac{-K_{t}}{J_{t}}, \\
a_{2}=\frac{p M}{J_{t} L_{r}} \\
b_{1}=-\frac{1}{T_{s} \sigma}+\frac{1}{T_{r}} \frac{1-\sigma}{\sigma L_{s} L_{r}} \\
a_{4}=\frac{1-\sigma}{\sigma} \frac{1}{M T_{r}}, \\
a_{5}=\frac{1-\sigma}{\sigma} \frac{p}{M}, \\
a_{6}=\frac{M}{T_{r}}, \\
a_{8}
\end{gathered}
$$

where $\omega_{g}$ is the angular speed of generator rotor and the $p$ is the number of pole pairs. $R_{s}, R_{r}, L_{s}, L_{r}$, and $M$ are the stator resistance, the rotor resistance, the stator inductance, the rotor inductance, and the mutual inductance of winding, respectively.

In the DFIG model (3), it can be found that the inputs of the generator subsystem contain the stator voltage $\left(\mathbf{u}_{s}\right)$, the rotor voltage $\left(\mathbf{u}_{r}\right)$, and the torque of wind turbine $\left(T_{a}\right)$. As reported in the work of [31], neither $\mathbf{u}_{s}$ nor $T_{a}$ can be selected as the control input, and the proper input should be only selected as the rotor voltage $\left(\mathbf{u}_{r}\right)$. The control outputs are the flux linkage amplitude of the rotor $\left|\lambda_{r}\right|^{2}$ and the electromagnetic torque $T_{\mathrm{em}}$ as follows:

$$
\mathbf{y}=\left(\begin{array}{l}
h_{1}(x) \\
h_{2}(x)
\end{array}\right)=\left(\begin{array}{c}
\left|\lambda_{r}\right|^{2} \\
T_{\mathrm{em}}
\end{array}\right)=\left(\begin{array}{c}
x_{4}^{2}+x_{5}^{2} \\
\mu\left(x_{2} x_{5}-x_{3} x_{4}\right)
\end{array}\right) .
$$

2.3. Design of the Cascade Controller. As the power generation subsystem of the wind power system has a much faster response performance than the mechanical drive subsystem, the robust controller of the mechanical and electrical subsystems can be separately designed to realize the global cascade control. The overall structure of the proposed controller is shown in Figure 3, which consists of the dual closed-loop structure and the global sliding-mode controller (GSMC) in 


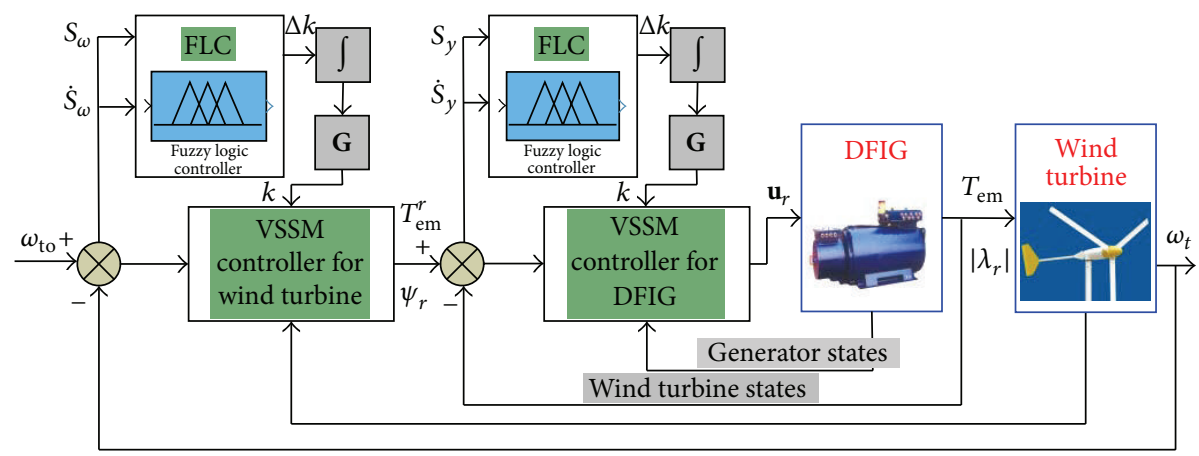

FIGURE 3: Fuzzy-logic-based variable structure control for wind turbines.

the inner ring to adjust the output electromagnetic torque of the DFIG and the amplitude of the rotor flux linkage, and the speed loop of the turbine blade is in the outer ring. The control output of the global system is the blade speed $\left(\omega_{t}\right)$, and the control goal is to obtain the max wind power by tracking the optimal blade speed $\left(\omega_{\text {to }}\right)$. In practice, it should be noticed that the pitch angle of the blade at the high wind speed can be used as the adjustable variable to limit the output of power. In this study, in order to simplify the design of the controller, it was assumed that the wind power system was operated under the rated power after the startup, indicating the wind speed was lower than the rated wind speed. Hence, it is not necessary to adjust the pitch angle $\beta$ in Figure 3 . In order to avoid the chattering phenomenon of the conventional VSSM control, two fuzzy systems were adopted to adaptively adjust the switch gains $\left(k_{i}\right)$ of the two VSSM controllers.

\section{Design of Robust Control of the DFIG Generation}

3.1. Linearization of the Input-Output Feedback. For the nonlinear system with exact parameters, the input-output feedback linearization technique is extremely suitable for the controller design. In this part, it is assumed that the model of the DFIG system has been accurately established, and the controller design will be completed using the input-output decoupling linearization.

Taking a derivative with respect to (5), we can get the following equation:

$$
\left(\begin{array}{c}
\dot{y}_{1} \\
\dot{y}_{2}
\end{array}\right)=\left(\begin{array}{c}
L_{f} h_{1} \\
L_{f} h_{2}
\end{array}\right)+\mathbf{G}_{r}\left(\begin{array}{c}
u_{r d} \\
u_{r q}
\end{array}\right)+\mathbf{G}_{s}\left(\begin{array}{c}
u_{s d} \\
u_{s q}
\end{array}\right)
$$

where the $L_{f} h(x)$ denotes the Lee derivative as follows:

$$
\begin{aligned}
L_{f} h_{1}= & 2\left(a_{6}\left(x_{2} x_{4}+x_{3} x_{5}\right)+a_{7}\left|\psi_{r}\right|^{2}\right), \\
L_{f} h_{2}= & \left(a_{3}+a_{7}\right) T_{\mathrm{em}} \\
& +\mu\left(a_{5}\left|\psi_{r}\right|^{2}-a_{8}\left(x_{2} x_{4}+x_{3} x_{5}\right)\right) x_{1},
\end{aligned}
$$

$$
\begin{aligned}
\mathbf{G}_{r} & =\left(\begin{array}{cc}
2 x_{4} & 2 x_{5} \\
\mu\left(b_{1} x_{5}-x_{3}\right) & \mu\left(x_{2}-b_{1} x_{4}\right)
\end{array}\right), \\
\mathbf{G}_{s} & =\left(\begin{array}{cc}
0 & 0 \\
\mu b_{2} x_{5} & -\mu b_{2} x_{4}
\end{array}\right) .
\end{aligned}
$$

The control input was selected as follows:

$$
\left(\begin{array}{l}
u_{r d} \\
u_{r q}
\end{array}\right)=-\mathbf{G}_{r}^{-1}\left(\left(\begin{array}{c}
L_{f} h_{1} \\
L_{f} h_{2}
\end{array}\right)+\mathbf{G}_{s}\left(\begin{array}{l}
u_{s d} \\
u_{s q}
\end{array}\right)-\left(\begin{array}{l}
v_{1} \\
v_{2}
\end{array}\right)\right) .
$$

Equation (6) can be decoupled into the reduced firstorder linear system as follows:

$$
\left(\begin{array}{l}
\dot{y}_{1} \\
\dot{y}_{2}
\end{array}\right)=\left(\begin{array}{l}
v_{1} \\
v_{2}
\end{array}\right) \text {. }
$$

In order to ensure the desired value of the rotor flux linkage as $y_{1 r}=\left|\psi_{r}\right|^{2}$ and the referenced electromagnetic torque $y_{2 r}=T_{\mathrm{em}}^{r}$ to be well tracked, the virtual control variable was designed as follows:

$$
\begin{aligned}
& v_{1}=-r_{2}\left(\left|\psi_{r}\right|^{2}-\lambda_{r}\right)+\dot{\lambda}_{r}, \\
& v_{2}=-r_{1}\left(T_{\mathrm{em}}-T_{\mathrm{em}}^{r}\right)+\dot{T}_{\mathrm{em}}^{r},
\end{aligned}
$$

where $r_{1}$ and $r_{2}$ are two parameters for adjusting the tracking rate.

3.2. Robust Variable Structure Controller Design. When there are the uncertainty and the parameter perturbation in the DFIG model, in order to improve the performance of the controller, it is necessary to adopt the robust control technique. In the sliding mode control system, the system motion can be divided into two phases: the first phase is the reaching stage, which means that the states will reach the desired sliding surface from an arbitrary initial state in a finite time under the switching control effort, and the second phase is the sliding-mode stage, which means to keep the system states henceforth remaining in the sliding surface under the equivalent control law. During the sliding-mode phase, the SMC is insensitive to parameter variations and complete rejection of disturbances. During the reaching phase, the conventional 
SMC is sensitive to system perturbations. Essentially, the robustness of the SMC may not be guaranteed if there exist large uncertainty and noise $[19,21]$. The solution to this problem in this paper is proposed by utilizing global sliding mode control (GSMC) instead of conventional SMC, which will eliminate the reaching phase of sliding mode control and the sliding-mode motion starts from the beginning [22]. Thus, the system has a strong robustness in the whole process.

Define the following control term:

$$
\mathbf{w}=\left(\begin{array}{c}
L_{f} h_{1} \\
L_{f} h_{2}
\end{array}\right)+\mathbf{G}_{s}\left(\begin{array}{l}
u_{s d} \\
u_{s q}
\end{array}\right) .
$$

Equation (6) can be modified as follows:

$$
\dot{\mathbf{y}}=w(\mathbf{x})+\mathbf{G}_{r} \mathbf{u}_{r} .
$$

Assume the parameter uncertainties in the DFIG model exist in the function $w(\mathbf{x})$ and the matrix $\mathbf{G}_{r}$ as follows:

$$
\begin{aligned}
\dot{\mathbf{y}} & =w(\mathbf{x})+\Delta w(\mathbf{x})+\mathbf{G}_{r} \mathbf{u}_{r}+\Delta \mathbf{G}_{r} \mathbf{u}_{r} \\
& =w(\mathbf{x})+\mathbf{G}_{r} \mathbf{u}_{r}+E(\mathbf{x})
\end{aligned}
$$

where $E(\mathbf{x})=\Delta w(\mathbf{x})+\Delta \mathbf{G}_{r} \mathbf{u}_{r}$ denotes the uncertainty induced by the parameter variation and the external disturbance.

Let $\mathbf{e}_{y}=\mathbf{y}-\mathbf{y}_{d}$, and it is defined as the tracking error, among which $e_{1}=\lambda_{r}-\left|\psi_{r}\right|^{2}$ and $e_{2}=T_{\mathrm{em}}-T_{\mathrm{em}}^{r}$. The global switching surface based on the speed tracking error was defined as follows:

$$
\mathbf{S}_{y}=\dot{\mathbf{e}}_{y}+\mathbf{C} \mathbf{e}_{y}-\mathbf{F}(t)
$$

where $\mathbf{C}=\operatorname{diag}\left(c_{1}, c_{2}\right)$ is the coefficient matrix and $\mathbf{F}(t)=$ $\left(f_{1}, f_{2}\right)^{T}$ is the designed function to realize the global slidingmode motion. In this work, we take $\mathbf{F}(t)=\mathbf{F}(t)=\mathbf{F}(0) \mathbf{e}_{y}^{-\lambda t}$.

Based on (13) and (14), the derivative of the switching surface can be derived as follows:

$$
\begin{aligned}
\dot{\mathbf{S}}_{y} & =\ddot{\mathbf{e}}_{y}+\mathbf{C} \cdot \dot{\mathbf{e}}_{y}-\dot{\mathbf{F}}(t) \\
& =\ddot{\mathbf{e}}_{y}-\dot{\mathbf{F}}(t)-\mathbf{C}\left[w(\mathbf{x})+\mathbf{G}_{r} \mathbf{u}_{r}+E(\mathbf{x})-\dot{\mathbf{y}}_{d}\right] .
\end{aligned}
$$

The DFIG rotor voltage control is computed as follows:

$$
\begin{aligned}
\mathbf{u}_{r}= & \left(\mathbf{C G}_{r}\right)^{-1} \\
& \cdot\left[-\ddot{\mathbf{e}}_{y}+\dot{\mathbf{F}}(t)-\mathbf{C} w(\mathbf{x})+\mathbf{C} \dot{\mathbf{y}}_{d}-\mathbf{K}_{y}(t) \operatorname{sgn}\left(\mathbf{S}_{y}\right)\right],
\end{aligned}
$$

where the notation $\operatorname{sgn}(\cdot)$ denotes the symbolic function. The $\mathbf{K}_{y}=\operatorname{diag}\left(k_{1}, k_{2}\right)$ denotes the switch gain matrix which satisfies the inequality $k_{i} \geqslant \max \left|E_{i}(\mathbf{x})\right|+\varepsilon_{i}$, and $E_{i}(\mathbf{x})$ denotes the $i$ th element of $E(\mathbf{x})$ and the parameter $\varepsilon_{i}>0$ is the design constant $(i=1,2)$.

To analyze the system stability, consider the following nonnegative Lyapunov function:

$$
V_{1}=\frac{1}{2} \mathbf{S}_{y}^{T} \mathbf{S}_{y}=\frac{1}{2} \sum_{i=1}^{2} s_{i}^{2} \geqslant 0 .
$$

By taking the derivation with respect to (17), the derivative of the Lyapunov function can be obtained as follows:

$$
\dot{V}_{1}=s_{1} \cdot \dot{s}_{1}+s_{2} \cdot \dot{s}_{2}
$$

By substituting (16) into (18), combining (13), and considering the value of the gain $\left(\mathbf{K}_{y}\right)$, it is not difficult to derive the following inequality:

$$
\begin{aligned}
\dot{V}_{1} & =\mathbf{S}_{y}^{T}\left[\mathbf{C E}(\mathbf{x})-\mathbf{K}_{y}(t) \operatorname{sgn}\left(\mathbf{S}_{y}\right)\right] \\
& \leqslant-\left(\varepsilon_{1}\left|s_{1}\right|+\varepsilon_{2}\left|s_{2}\right|\right) \leqslant 0 .
\end{aligned}
$$

From (17) and (19), it can be found that the system is stable which can realize the global sliding-mode motion. Moreover, the tracking error will be converged to zero as well as $T_{\mathrm{em}} \rightarrow$ $T_{\mathrm{em}}^{r}$ and $\lambda_{r} \rightarrow\left|\psi_{r}\right|^{2}$.

\section{Design of Robust Control of the Wind Turbine}

4.1. Linearization of the Input-Output Feedback. The motion equation of the wind turbine can be derived from (2) as follows:

$$
J_{t} \dot{\omega}_{t}=T_{a}-K_{t} \omega_{t}-T_{g}
$$

The first-order reference model of the rotor speed tracking error is designed as follows:

$$
\dot{e}_{\omega}+k_{0} e_{\omega}=0 .
$$

In (21), the error $\left(e_{\omega}=\omega_{\text {to }}-\omega_{t}\right)$ and the constant $\left(k_{0}>0\right)$ are used to adjust the converging rate.

According to the work of [20], the control torque is computed as follows:

$$
T_{g}=T_{a}-K_{t} \omega_{t}-J_{t} k_{0} e_{\omega}-J_{t} \dot{\omega}_{\text {to }}
$$

Due to various factors in practice, the actual values of the whole inertia $\left(K_{t}\right)$ and the external friction coefficient $\left(J_{t}\right)$ will deviate from the nominal values of $K_{t n}$ and $J_{t n}$. These differences will undoubtedly affect the dynamic performance of the speed tracking and lead to the reduction of control accuracy. So this design has a lack of the robustness for the uncertain parameters.

4.2. Robust Variable Structure Controller Design. When the model uncertainty and the parameter perturbation exist, in order to improve the controller performance, it is necessary to design the robust wind turbine controller using the GSMCbased VSSM control to realize the tracking control of the optimal $\omega_{\text {to }}$.

The motion equation (2) of the wind turbine can be modified as follows:

$$
\dot{\omega}_{t}+a \omega_{t}+d=b T_{g}
$$

where $a=K_{t} / J_{t}, d=-T_{a} / J_{t}$, and $b=-1 / J_{t}$. 
Considering the parameter variations and the uncertain factors during the running of the wind turbine, (23) could be modified as follows:

$$
\dot{\omega}_{t}+(a+\Delta a) \omega_{t}+(d+\Delta d)=(b+\Delta b) T_{g} .
$$

In (24), the notations $\Delta a, \Delta b$, and $\Delta d$ represent the parameter perturbation or disturbance of the DFIG. The tracking error of the blade speed is defined as follows:

$$
e_{3}=\omega_{t}-\omega_{\mathrm{to}}
$$

where $\omega_{\text {to }}$ is the optimal blade speed. By taking the derivation with respect to (25), the derivative of the tracking error can be obtained as follows:

$$
\begin{aligned}
\dot{e}_{3} & =\dot{\omega}_{t}-\dot{\omega}_{\text {to }} \\
& =-(a+\Delta a) \omega_{t}-(d+\Delta d)+(b+\Delta b) T_{g}-\dot{\omega}_{\text {to }} \\
& =-a \omega_{t}-d+b T_{g}-\dot{\omega}_{\text {to }}+z(t) .
\end{aligned}
$$

In (26), $z(t)$ denotes the sum of the uncertainties induced by the parameter perturbation as follows:

$$
z(t)=-\Delta a \omega_{t}-\Delta d+\Delta b T_{g}
$$

In the next part, we first design the switch function of the VSSM speed controller as $s_{3}$ and then provide the control law of the VSSM speed controller. The aim of the robust speed control is to make the error $\left(e_{3}\right)$ rapidly converge to zero, so we design a global switching function with respect to the speed error as follows:

$$
s_{3}=\dot{e}_{3}+c_{3} e_{3}-f_{3}(t)
$$

Based on (28), it can be obtained as follows:

$$
\begin{aligned}
\dot{s}_{3} & =\ddot{e}_{3}+c_{3} \dot{e}_{3}-\dot{f}_{3}(t) \\
& =\ddot{e}_{3}-\dot{f}_{3}(t)-c_{3}\left[-a \omega_{t}-d+b T_{g}-\dot{\omega}_{\text {to }}+z(t)\right] .
\end{aligned}
$$

And the generator torque is designed as follows:

$$
\begin{aligned}
T_{g}= & \left(c_{3} b\right)^{-1} \\
& \cdot\left[-\ddot{e}_{3}+\dot{f}_{3}(t)-c_{3} \dot{\omega}_{\mathrm{to}}+c_{3} a \omega_{t}+c_{3} d-k_{3}(t) \operatorname{sgn}\left(s_{3}\right)\right] .
\end{aligned}
$$
tion:

Now, consider the following nonnegative Lyapunov func-

$$
V_{2}=\frac{1}{2} s_{3}^{2} \geqslant 0
$$

The derivative of $V_{2}$ can be solved as follows:

$$
\dot{V}_{2}=s_{3} \dot{s}_{3}=s_{3}\left[c_{3} z(t)-k_{3}(t) \operatorname{sgn}\left(s_{3}\right)\right] .
$$

To ensure the control law (30) satisfying the essential arrival condition of the sliding-mode motion, it is necessary to design a proper switch gain $\left(k_{3}\right) . k_{3}$ satisfies the condition as follows:

$$
k_{3}(t)=c_{3} \cdot \max |z(t)|+\varepsilon_{3},
$$

where we can obtain the inequality $d\left(V_{2}(t)\right) / d t \leqslant-\varepsilon_{3}\left|s_{3}\right|$ from (33). Moreover, since the Lyapunov candidate $V_{2}(t)$ is obviously positive definite, the speed error will be converged, and $V_{2}(t)$ will become infinite when the $s_{3}$ approaches infinites. The equilibrium point of the system is globally asymptotical converged and stable. So we can obtain a robust controller for the blade speed according to the control law in (30).

\section{Adaptive Fuzzy Control of the Switch Gains}

In the controllers of (16) and (30), it is shown that the gain of the VSSM switch control $\left(k_{i}(t)\right)$ is directly related to the upper bound of the system uncertainties and the external disturbances. If the upper bound is very high, the too large switch control gain $\left(k_{i}(t)\right)$ will definitely cause the undesired chattering of the control input irregularly. And the large chattering will cause the instability of the blade rotation and even a lot of wear and tear of the blade, which leads to a waste of energy capture and decreases the available output of the converted electrical energy. To overcome the above disadvantage of the SMC controller, in this work, we adopted the adaptive fuzzy inference strategy, instead of the fixed gains, to deduce the adjustable switch gain. Since the switch function $\left(s_{i}(t)\right)$ and its derivation $(\dot{s}(t))$ reflect the location of the phase point in the phase plane and its motion speed, we selected $s_{i}(t)$ and $\dot{s}_{i}(t)$ as the control inputs of the fuzzy logic control (FLC); through the fuzzy inference technique, the proper control increment of the output switch gain $\left(\Delta k_{i}(t)\right)$ is derived as well as the required switch gain $(k(t))$.

The fuzzy logic controller is constructed with single input and single output, and the input and output are, respectively, the $s_{i} \cdot \dot{s}_{i}$ and $\Delta k_{i}(t)(i=1,2$, and 3). The first step in the design of a FLC is to define the linguistic variable, which are expressed as follows:

$$
\begin{aligned}
s_{i} \cdot \dot{s}_{i} & =\{\mathrm{NL}, \mathrm{NM}, \mathrm{ZO}, \mathrm{PM}, \mathrm{PL}\} \\
\Delta k_{i}(t) & =\{\mathrm{NL}, \mathrm{NS}, \mathrm{ZO}, \mathrm{PS}, \mathrm{PL}\}
\end{aligned}
$$

where $\mathrm{N}$ means "negative," $\mathrm{P}$ means "positive," L means "large," M means "medium," S means "small," and ZO means "zero."

The universe of the variable values of the input and output are defined in the ranges as $s_{i} \cdot \dot{s}_{i}=\{-3,-2,0,2,3\}$ and $\Delta k_{i}=$ $\{-3,-1,0,1,3\}$, respectively. The next step is to complete the input fuzzification of $s_{i} \cdot \dot{s}_{i}$ and $\Delta k_{i}(t)$. There are tradeoffs when selecting the number of fuzzy subsets and the shape of the membership function. To minimize computational complexity, the sigmoid type and the Gaussian membership functions are selected in this work as in Figure 4.

In the design of fuzzy controller, on one hand, it is necessary to ensure the existence and arrival conditions for the sliding mode motion; that is, the inequality of $s_{i} \cdot \dot{s}_{i}<0$ must be satisfied for the design of $\Delta k_{i}(t)$. On the other side, 


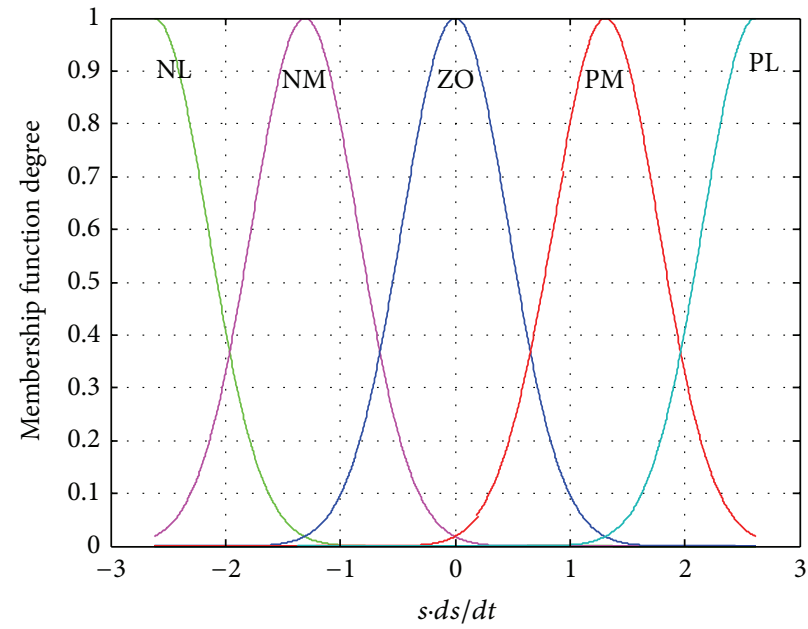

(a)

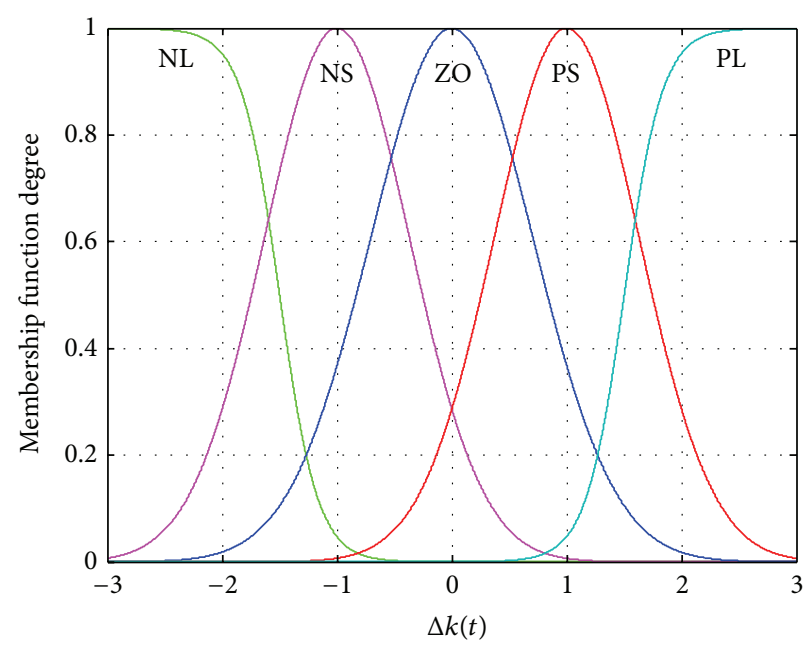

(b)

FIgURE 4: Membership function degree for the input and output of the fuzzy inference system. (a) The input $s_{i} \cdot \dot{s}_{i}$; (b) the output $\Delta k_{i}(t)$.

the large switch control gain should be taken when the phase point is far away from the sliding-mode plane, while the small switch control gain should be taken when the phase point is near the sliding-mode plane to reduce the speed at which the phase trajectory passes through the sliding-mode plane $\left(s_{i}(t)=0\right)$. Consequently, the value of the gain $\left(k_{i}(t)\right)$ should satisfy the following fuzzy rules.

Rule 1: if the $s_{i} \cdot \dot{s}_{i}>0$, the value of $k_{i}(t)$ should decrease.

Rule 2: if the $s_{i} \cdot \dot{s}_{i}>0$, the value of $k_{i}(t)$ should increase.

With these rules, if the $s_{i} \cdot \dot{s}_{i}$ is positive and large "PB" when both the $s_{i}(t)$ and $\dot{s}_{i}$ are positive and large (or negative and large), it is necessary for the control input to have a large and positive $(\mathrm{PB})$ increment to allow $s_{i} \cdot \dot{s}_{i}$ to rapidly decrease. If the $s(t)$ is zero, $s_{i} \cdot \dot{s}_{i}$ and $\Delta k_{i}(t)$ should be zero too, which is just the desired sliding-mode states. If the value of $s_{i} \cdot \dot{s}_{i}$ lies between the above two situations, the system state approaches to the switch plane of the sliding mode, and it is only needed to provide a small control increment in the same direction. Then, the fuzzy inference rules of the FLC controller can be obtained as follows.

Rule 1: If $s_{i} \cdot \dot{s}_{i}$ is PL, then $\Delta k_{i}(t)$ is PL.

Rule 2: If $s_{i} \cdot \dot{s}_{i}$ is PM, then $\Delta k_{i}(t)$ is PS.

Rule 3: If $s_{i} \cdot \dot{s}_{i}$ is ZO, then $\Delta k_{i}(t)$ is ZO.

Rule 4: If $s_{i} \cdot \dot{s}_{i}$ is NM, then $\Delta k_{i}(t)$ is NS.

Rule 5: If $s_{i} \cdot \dot{s}_{i}$ is NL, then $\Delta k_{i}(t)$ is NL.

The designed rules above make a compromise between the high speed tracking oscillations and a smooth output. The last step for the FLC design is to the defuzzification of the output, and the centre of average method is used to realize the controller's output.

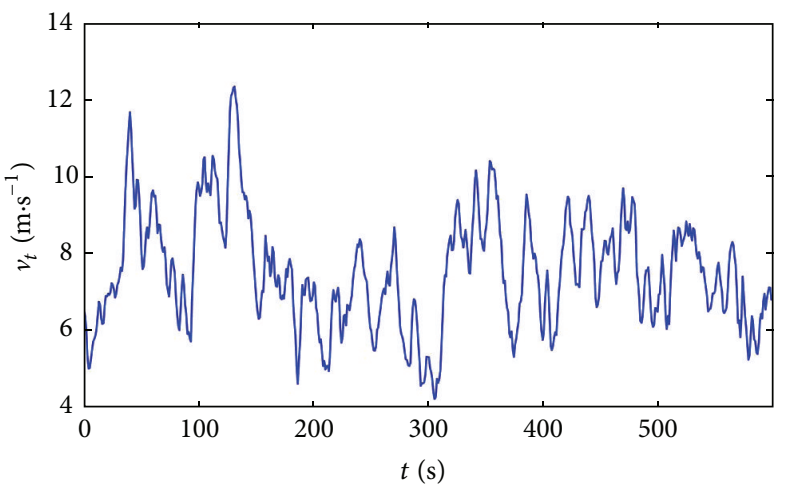

Figure 5: Profile of simulated wind speed.

After obtaining the $\Delta k_{i}(t)$, the upper bound of the $k_{i}(t)$ is estimated using the following integrator:

$$
\widehat{k}_{i}(t)=G_{i} \int_{0}^{t} \Delta k_{i} \mathrm{~d} t
$$

where the $G_{i}$ is the scaling coefficient $\left(G_{i}>0\right)$.

The $k_{i}(t)$ in (16) and (30) is replaced by its estimation to realize the design of the VSSM controller based on the fuzzy logic. The structure of the overall control system is shown in Figure 3.

\section{Simulation Results and Analysis}

The simulations for the propose cascade fuzzy-logic based sliding-mode control (F-SMC) were carried out, and the simulated results were compared for the performance with that obtained using the feedback linearization method. The related characteristic parameters of the wind turbine and the dual-feed generator are listed in Tables 1 and 2, respectively. As in Figure 5, the simulated average wind speed was $7.5 \mathrm{~m} / \mathrm{s}$ based on the wind speed curve reported in [31]. 


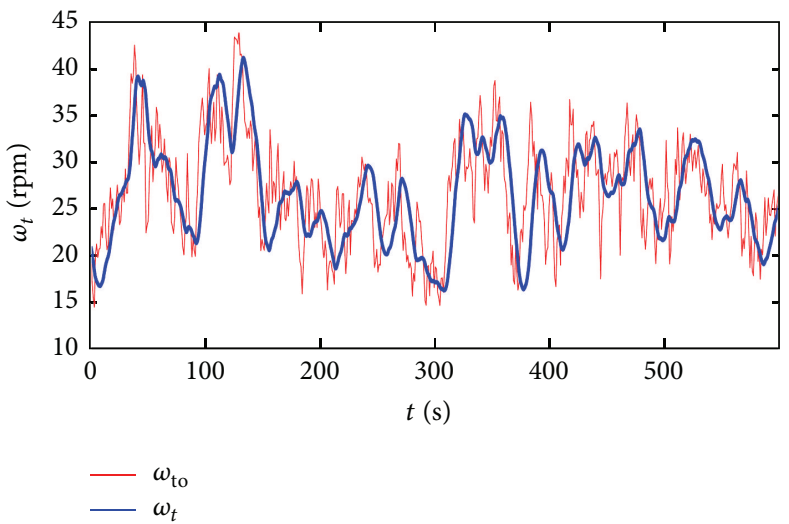

(a)

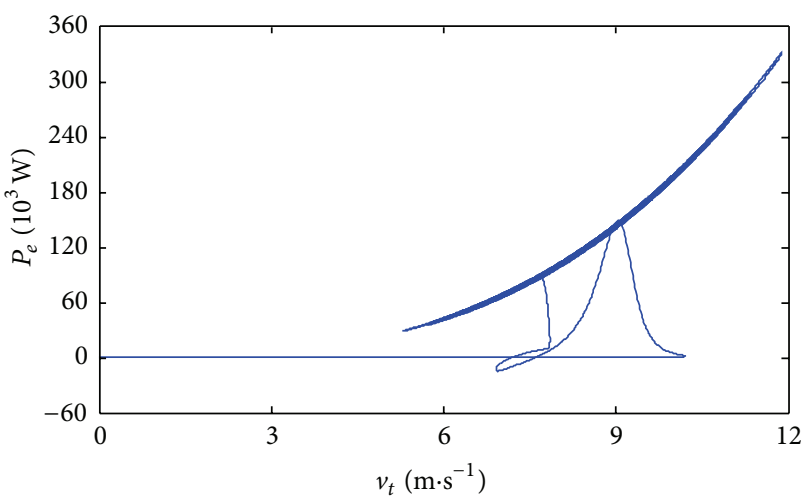

(c)

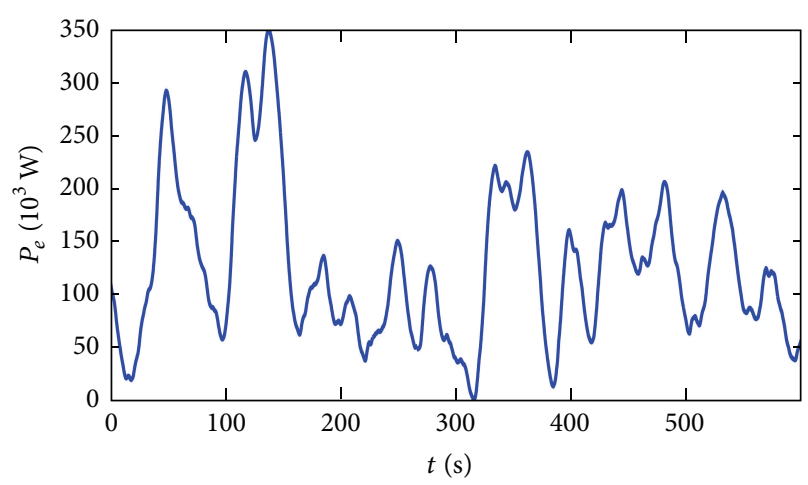

(b)

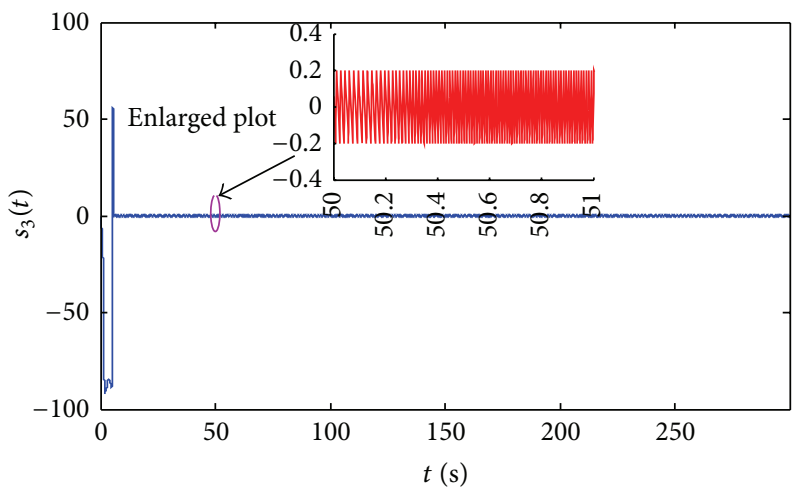

(d)

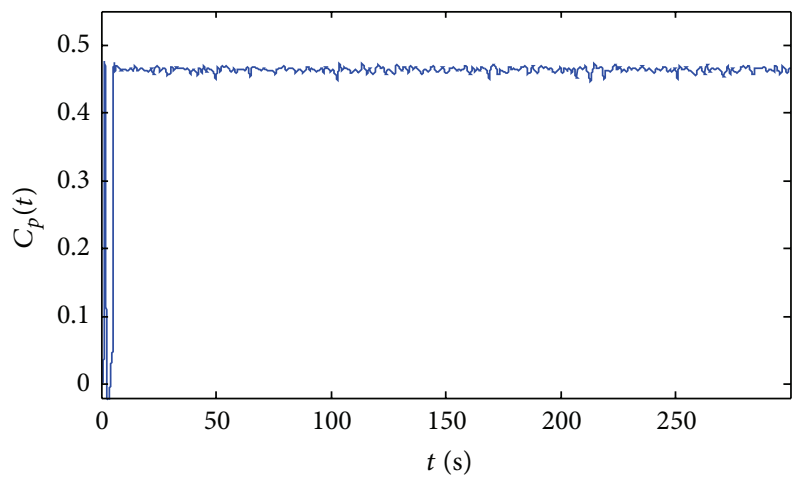

(e)

FIGURE 6: Blade rotor speed tracking and generation power with the proposed method. (a) Optimal speed tracking; (b) generation power; (c) phase diagram between generator output power and wind speed; (d) switching function of blade speed; and (e) power coefficient.

Figure 6(a) shows the actual speed of the blade $\left(\omega_{t}\right)$ under the proposed control method F-SMC, and it can be found that the actual speed can well track the optimal speed $\left(\omega_{\text {to }}\right)$. Figure 6(b) shows the generation power with the proposed controller. Figure 6(c) shows the phase diagram between the generator output power and the wind speed, from which it can be observed that, after a short time settling at startup, in most of the time, the output power rises approximately linear with the actual wind speed with a small curvature. In fact, if the wind speed is under the rated speed and above the startup speed, Figure 6(c) proves the general understanding that wind speed gets bigger and available output power becomes bigger accordingly. Figure 6(d) gives the switching surface of the blade speed and its enlargement between $t=50 \sim 51 \mathrm{~s}$, and it is observed that the system enters the sliding-mode motion within several seconds and the speed tracking error approaches zero. In Figure 6(e), the curve represents the timevarying power coefficient, and it shows that the actual power efficient achieves the optimal value (0.44) in a short time and fluctuates slightly around this value as the wind speed varies. 


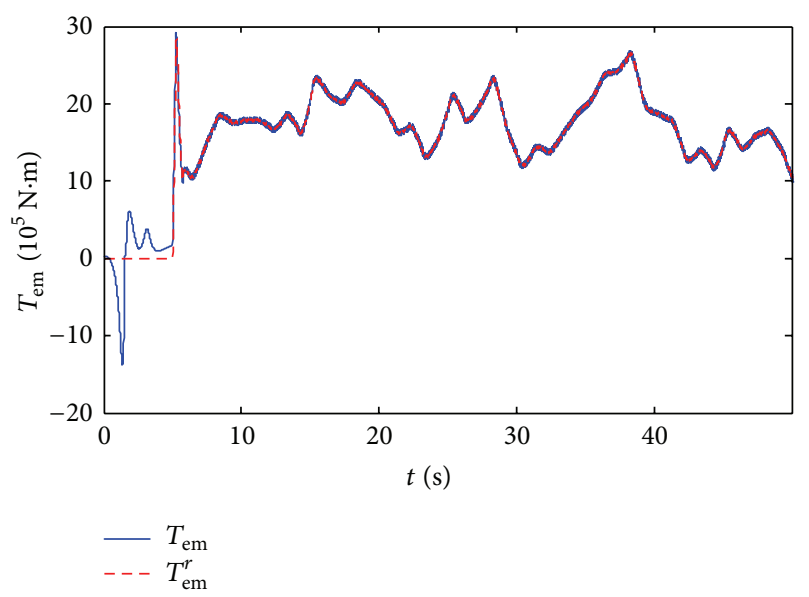

(a)

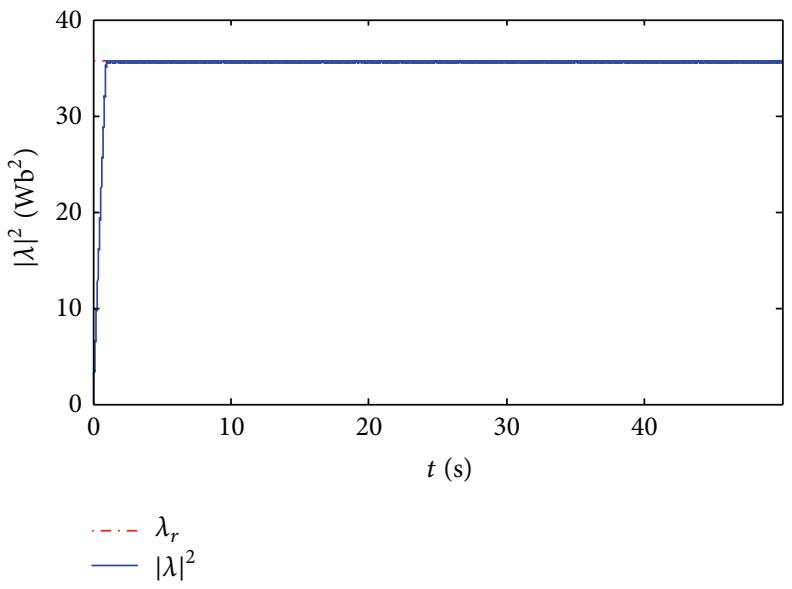

(b)

FIGURE 7: Dynamic responses of DFIG with system uncertainties. (a) Torque response; (b) flux response.

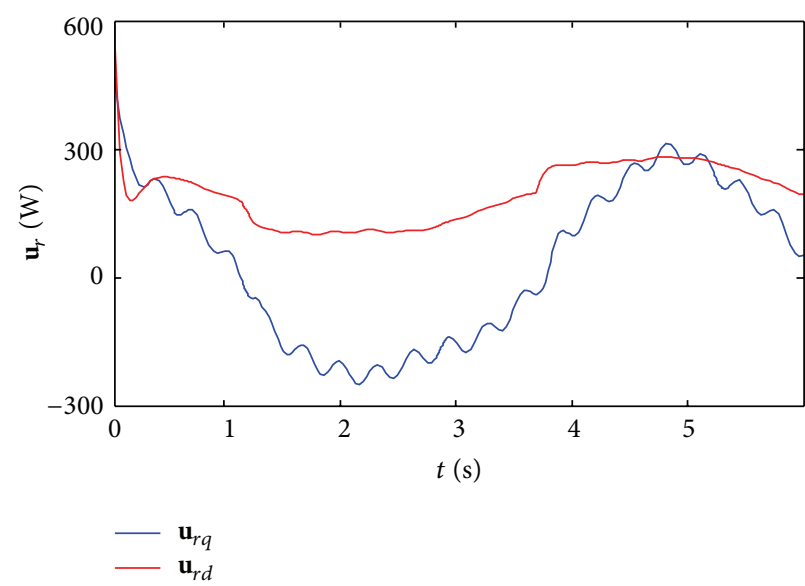

(a)

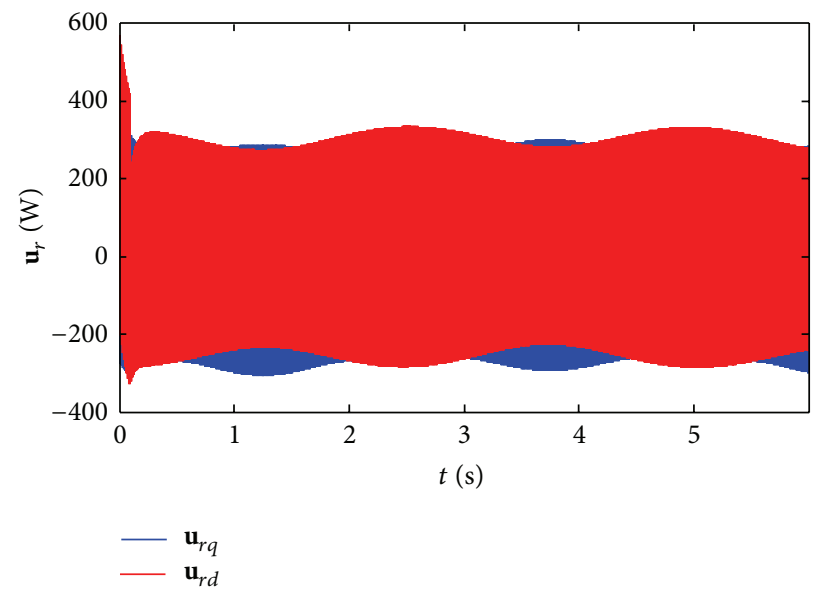

(b)

FIGURE 8: The control inputs under the proposed F-SMC method in this work and the conventional sliding mode control method: (a) the proposed scheme; (b) the conventional sliding mode control.

TABLE 1: The parameters of the wind turbine for simulation.

\begin{tabular}{lcc}
\hline Parameter & Unit & Value \\
\hline The blade radius $(R)$ & $\mathrm{m}$ & 21.65 \\
The rated power & $\mathrm{kW}$ & 600 \\
The whole of the rotor $\left(J_{t}\right)$ & $\mathrm{kg} \cdot \mathrm{m}^{2}$ & $3.92 \times 10^{5}$ \\
The friction coefficient $\left(K_{t}\right)$ & $\mathrm{N} \cdot \mathrm{m} \cdot \mathrm{rad}^{-1} \cdot \mathrm{s}$ & 400 \\
The increasing ratio of the gear case $\left(n_{g}\right)$ & $/$ & 43.165 \\
The air density $(\rho)$ & $\mathrm{kg} / \mathrm{m}^{3}$ & 1.0308 \\
The maximum rotor torque & $\mathrm{kN} \cdot \mathrm{m}$ & 162 \\
\hline
\end{tabular}

When the simulation started, the resistance variations of both the stator and the rotor were set to be $150 \%$ of their nominal values, and the moment of the inertia $\left(J_{t}\right)$ and friction coefficient $\left(K_{t}\right)$ of the wind turbine were also increased by $40 \%$. Figure 7 shows the curves of the torque response and the flux linkage response, and it can be observed that the desired electromagnetic torque and the flux linkage amplitude can be achieved within 2 seconds.

Figure 8 shows the curves of the control inputs both under our proposed F-SMC method and the conventional sliding mode controller, and it can be observed that the proposed scheme can efficiently remove the chattering of the rotor voltage because of the fuzzy adaptation on the switching gains. On the other hand, as in Figure 8(b), the chattering phenomenon in the control input can not be ignored and is harmful to the wind turbine, which will more likely be fatigued.

Figure 9 shows the performance comparison of the optimal blade speed tracking and the output electrical energy between the proposed F-SMC in this work and the feedback linearization (FL) methods [4]. Under the large variation of the turbine/DFIG parameters, the conventional FL controller can not realize the real-time tracking and the control performance of the blade speed is not satisfied as shown in 


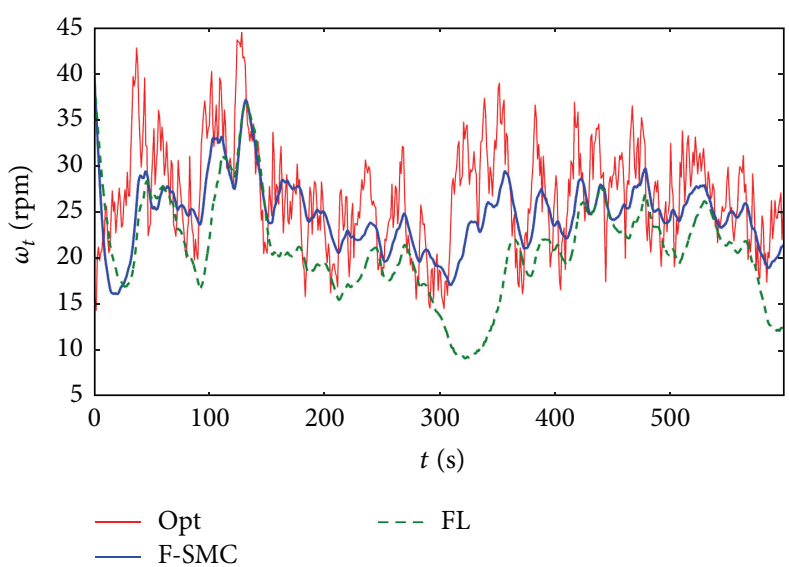

(a)

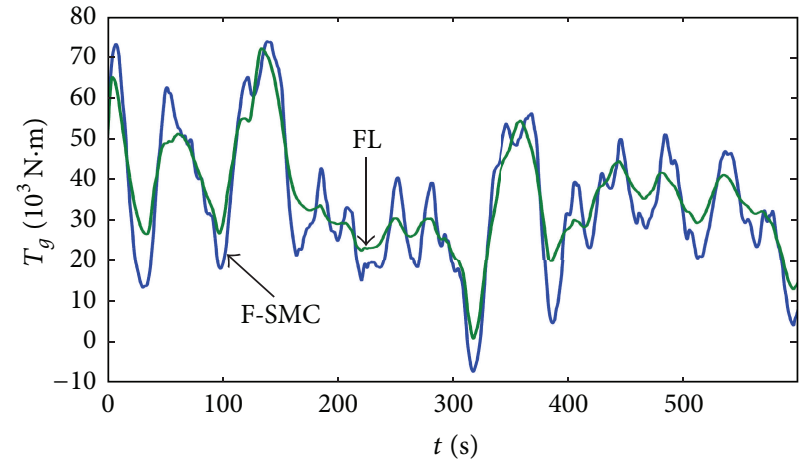

(b)

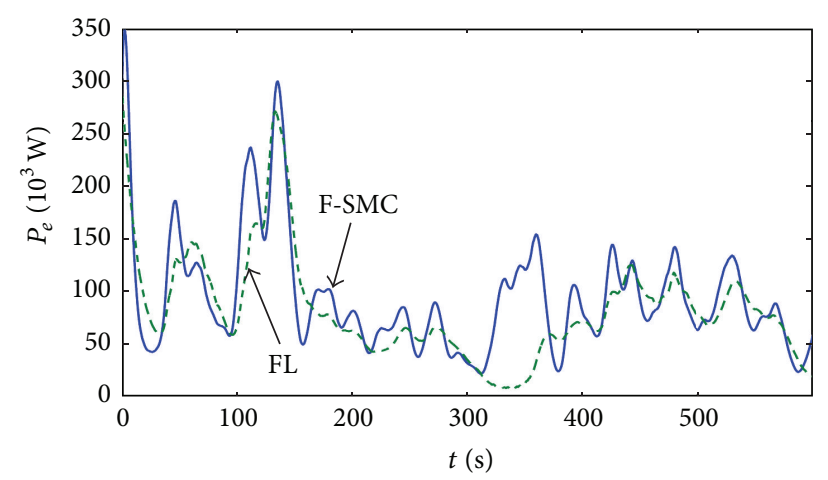

(c)

FIGURE 9: Performance comparison between the proposed F-SMC method in this work and the feedback linearization (FL) method: (a) blade rotor speed tracking; (b) generated torque; and (c) generation power.

TABLE 2: The parameters of the three-phase dual-feed induction generator.

\begin{tabular}{lcc}
\hline Parameter & Unit & Value \\
\hline The rated power & $\mathrm{kW}$ & 660 \\
The rated voltage of the stator & $\mathrm{V}$ & 690 \\
The rated frequency & $\mathrm{Hz}$ & 50 \\
The number of the pair of poles & $/$ & 3 \\
The stator resistance & $\Omega$ & 0.115 \\
The leakage inductance of the stator & $\mathrm{mH}$ & 1.65 \\
The rotator resistance & $\Omega$ & 0.184 \\
The leakage inductance of the rotator & $\mathrm{mH}$ & 1.68 \\
The mutual inductance & $\mathrm{mH}$ & 46.6 \\
The moment of the inertia & $\mathrm{kg} \cdot \mathrm{m}^{2}$ & 0.334 \\
\hline
\end{tabular}

Figure 9(a), but our proposed F-SMC method can well catch the variation trend of the wind speed and performs optimally speed tracking. Moreover, the output electrical energy generated by the F-SMC method in Figure 9(c) is more than that of the feedback linearization method, indicating that it can capture more wind energy and exhibit higher utilization efficiency of the wind energy.

\section{Conclusions}

Blade speed and output electrical power control in wind turbines have a great importance due to variable and uncontrollable wind velocities. This paper presented the modeling of doubly fed induction generator based variable-speed wind turbine and developed a novel robust control scheme. The goal of this work was to make use of VSSM to effectively improve the speed and output power control despite of the motor's and turbine's parameter variations. Both theoretical analysis and computer simulation results verify that high performance can be achieved with the proposed control method. Compared to previous results in the literatures, the main features of the proposed design can be summarized as follows.

(1) The proposed F-SMC control design ensures optimal operation of the DFIG and wind turbine under variable wind velocity and perturbations; thus robust tracking on the optimal speed and maximum wind energy capture are derived in the whole process; to the best of our knowledge, it is the first time to apply the global sliding mode control into the wind turbine controller design.

(2) The fuzzy-logic-based inference system is adopted to adjust the switching gains of the F-SMC controller 
with minimized control action, and this leads to a reduction of the system chattering to acceptable levels while still maintaining good tracking on the desired variables.

(3) The computation burden of the propose design is not high and is costly effective to be implemented in practice due to the simplicity of SMC techniques, compared to some existing controller schemes.

Overall, these features make our design very attractive and readily applicable to the robust control of variable-speed/ fixed pitch wind turbines. Further development of this novel control scheme to tackle problems such as grid-connected power generation and low-voltage ride through and the independent variable pitch control is subject of future work.

\section{Conflict of Interests}

The authors declare that there is no conflict of interests regarding the publication of this paper.

\section{Acknowledgments}

The authors are grateful to the support of the National Natural Science Foundation of China (61203019), the China Postdoctoral Science Foundation funded Project (2012M521518), the Key Projects of Chinese Ministry of Education (no. 212122), the Department of Education (14A032) and Innovative Research Team in Higher Educational Institutions of Hunan Province, and the Natural Science Foundation of Hunan Provincial (no. 13JJ9019).

\section{References}

[1] The World Wind Energy Association, World Wind Energy Report 2012, WWEA Head Office, Bonn, Germany, 2013.

[2] A. Zervos, Wind Energy - The Facts: A Guide to the Technology, Economics and Future of Wind Power, European Wind Energy Association, Brussels, Belgium, 2009.

[3] Chinese Wind Energy Association, 2013 Annual Review and Outlook on China Wind Power, CWEA Head Office, Beijing, China, 2013.

[4] I. Muntean, A. I. Bratcu, N. A. Cutululis, and E. Ceanga, Optimal Control of Wind Energy Systems, Springer, London, UK, 2008.

[5] L. M. Fernandez, C. A. Garcia, and F. Jurado, "Comparative study on the performance of control systems for doubly fed induction generator (DFIG) wind turbines operating with power regulation," Energy, vol. 33, no. 9, pp. 1438-1452, 2008.

[6] H. Altun and S. Sünter, "Modeling, simulation and control of wind turbine driven doubly-fed induction generator with matrix converter on the rotor side," Electrical Engineering, vol. 95, no. 2, pp. 157-170, 2013.

[7] S. Müller, M. Deicke, and R. W. De Doncker, "Doubly fed induction generator systems for wind turbines," IEEE Industry Applications Magazine, vol. 8, no. 3, pp. 26-33, 2002.

[8] N. R. Ullah and T. Thiringer, "Variable speed wind turbines for power system stability enhancement," IEEE Transactions on Energy Conversion, vol. 22, no. 1, pp. 52-60, 2007.

[9] Y. Bao, H. Wang, and J. Zhang, "Adaptive inverse control of variable speed wind turbine," Nonlinear Dynamics, vol. 61, no. 4, pp. 819-827, 2010.
[10] E. Koutroulis and K. Kalaitzakis, "Design of a maximum power tracking system for wind-energy-conversion applications," IEEE Transactions on Industrial Electronics, vol. 53, no. 2, pp. 486-494, 2006.

[11] B. Boukhezzar and H. Siguerdidjane, "Nonlinear control with wind estimation of a DFIG variable speed wind turbine for power capture optimization," Energy Conversion and Management, vol. 50, no. 4, pp. 885-892, 2009.

[12] F. Wu, X.-P. Zhang, P. Ju, and M. J. H. Sterling, “Decentralized nonlinear control of wind turbine with doubly fed induction generator," IEEE Transactions on Power Systems, vol. 23, no. 2, pp. 613-621, 2008.

[13] J.-H. Guo, L.-H. Zhang, and X. Cai, "Exact linearization control scheme of DFIG," Electric Machines and Control, vol. 13, no. 1, pp. 57-62, 2009.

[14] C. L. Xia, Q. Geng, X. Gu et al., "Input-output feedback linearization and speed control of a surface permanent-magnet synchronous wind generator with the boost-chopper converter," IEEE Transaction on Industrial Electronics, vol. 59, no. 9, pp. 3489-3500, 2012.

[15] M. F. Ren, J. H. Zhang, Y. Tian et al., "A neural network controller for variable-speed variable-pitch wind energy conversion systems using generalized minimum entropy criterion," Mathematical Problems in Engineering, vol. 2014, Article ID 412027, 9 pages, 2014.

[16] X. Yao, X. Su, and L. Tian, "Wind turbine control strategy at lower wind velocity based on neural network PID control," in Proceedings of the International Workshop on Intelligent Systems and Applications (ISA '09), vol. 1, pp. 1-5, Wuhan, China, May 2009.

[17] J.-W. Perng, G.-Y. Chen, and S.-C. Hsieh, "Optimal pid controller design based on PSO-RBFNN for wind turbine systems," Energies, vol. 7, no. 1, pp. 191-209, 2014.

[18] U. Ozbay, E. Zergeroglu, and S. Sivrioglu, "Adaptive backstepping control of variable speed wind turbines," International Journal of Control, vol. 81, no. 6, pp. 910-919, 2008.

[19] H. De Battista and R. J. Mantz, "Dynamical variable structure controller for power regulation of wind energy conversion systems," IEEE Transactions on Energy Conversion, vol. 19, no. 4, pp. 756-763, 2004.

[20] J. Matas, M. Castilla, J. M. Guerrero, L. G. de Vicuña, and J. Miret, "Feedback linearization of direct-drive synchronous wind-turbines via a sliding mode approach," IEEE Transactions on Power Electronics, vol. 23, no. 3, pp. 1093-1103, 2008.

[21] G. W. Cai, C. Liu, D. Y. Yang, and N. T. Huang, "Design of nonlinear robust rotor current controller for DFIG based on terminal sliding mode control and extended state observer," Mathematical Problems in Engineering, vol. 2014, Article ID 201938, 13 pages, 2014.

[22] L. Liu, Z. Han, and W. Li, "Global sliding mode control and application in chaotic systems," Nonlinear Dynamics, vol. 56, no. 1-2, pp. 193-198, 2009.

[23] A. Gholami and A. H. Markazi, "A new adaptive fuzzy sliding mode observer for a class of MIMO nonlinear systems," Nonlinear Dynamics, vol. 70, no. 3, pp. 2095-2105, 2012.

[24] V. Galdi, A. Piccolo, and P. Siano, "Designing an adaptive fuzzy controller for maximum wind energy extraction," IEEE Transactions on Energy Conversion, vol. 23, no. 2, pp. 559-569, 2008.

[25] C. Jauch, T. Cronin, P. Sørensen, and B. B. Jensen, "A fuzzy logic pitch angle controller for power system stabilization," Wind Energy, vol. 10, no. 1, pp. 19-30, 2007. 
[26] A. G. Aissaoui, A. Tahour, M. Abid, N. Essounbouli, and F. Nollet, "A fuzzy sliding mode-based power control design for wind turbine," in Proceedings of the 2nd International Symposium on Environment Friendly Energies and Applications (EFEA '12), pp. 329-335, London, UK, June 2012.

[27] X. Yao, Y. Liu, and C. Guo, "Adaptive fuzzy sliding-mode control in variable speed adjustable pitch wind turbine," in Proceedings of the IEEE International Conference on Automation and Logistics (ICAL '07), pp. 313-318, Jinan, China, August 2007.

[28] S. Abdeddaim and A. Betka, "Optimal tracking and robust power control of the DFIG wind turbine," International Journal of Electrical Power and Energy Systems, vol. 49, no. 1, pp. 234242, 2013.

[29] D. Kairous and R. Wamkeue, "DFIG-based fuzzy sliding-mode control of WECS with a flywheel energy storage," Electric Power Systems Research, vol. 93, pp. 16-23, 2012.

[30] K. Boulâam and A. Boukhelifa, "A fuzzy sliding mode control for DFIG-based wind turbine power maximization," in Proceedings of the 7th IET International Conference on Power Electronics, Machines and Drives (PEMD '14), pp. 1-6, Manchester, UK, April 2014.

[31] P. Andreas, Analysis, modeling and control of doubly fed induction generators for wind turbines [Ph.D. thesis], Chalmers University of Technology, Gothenburg, Sweden, 2005. 


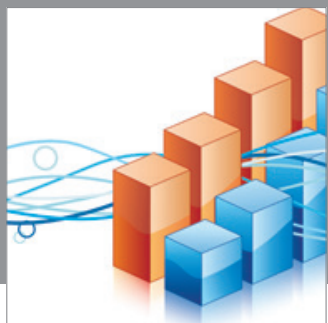

Advances in

Operations Research

mansans

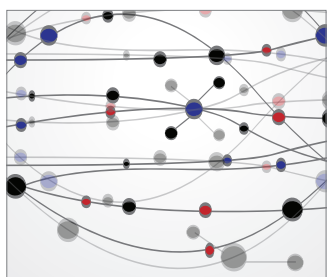

The Scientific World Journal
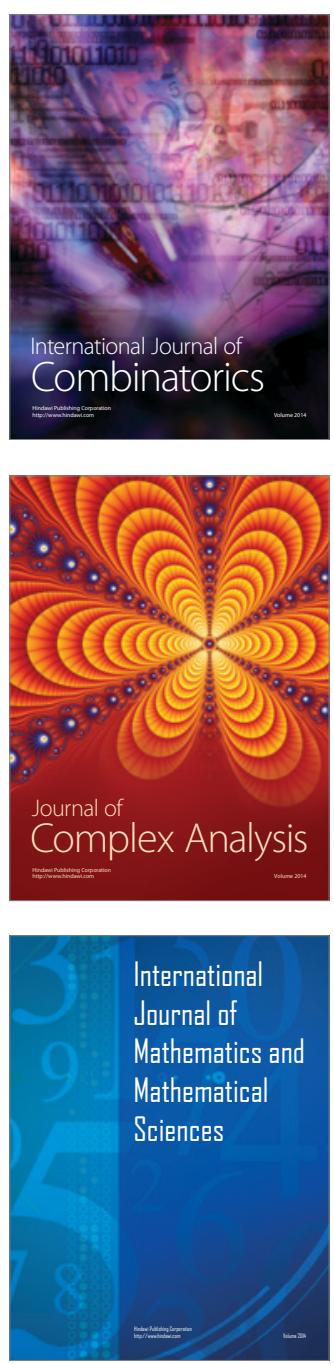
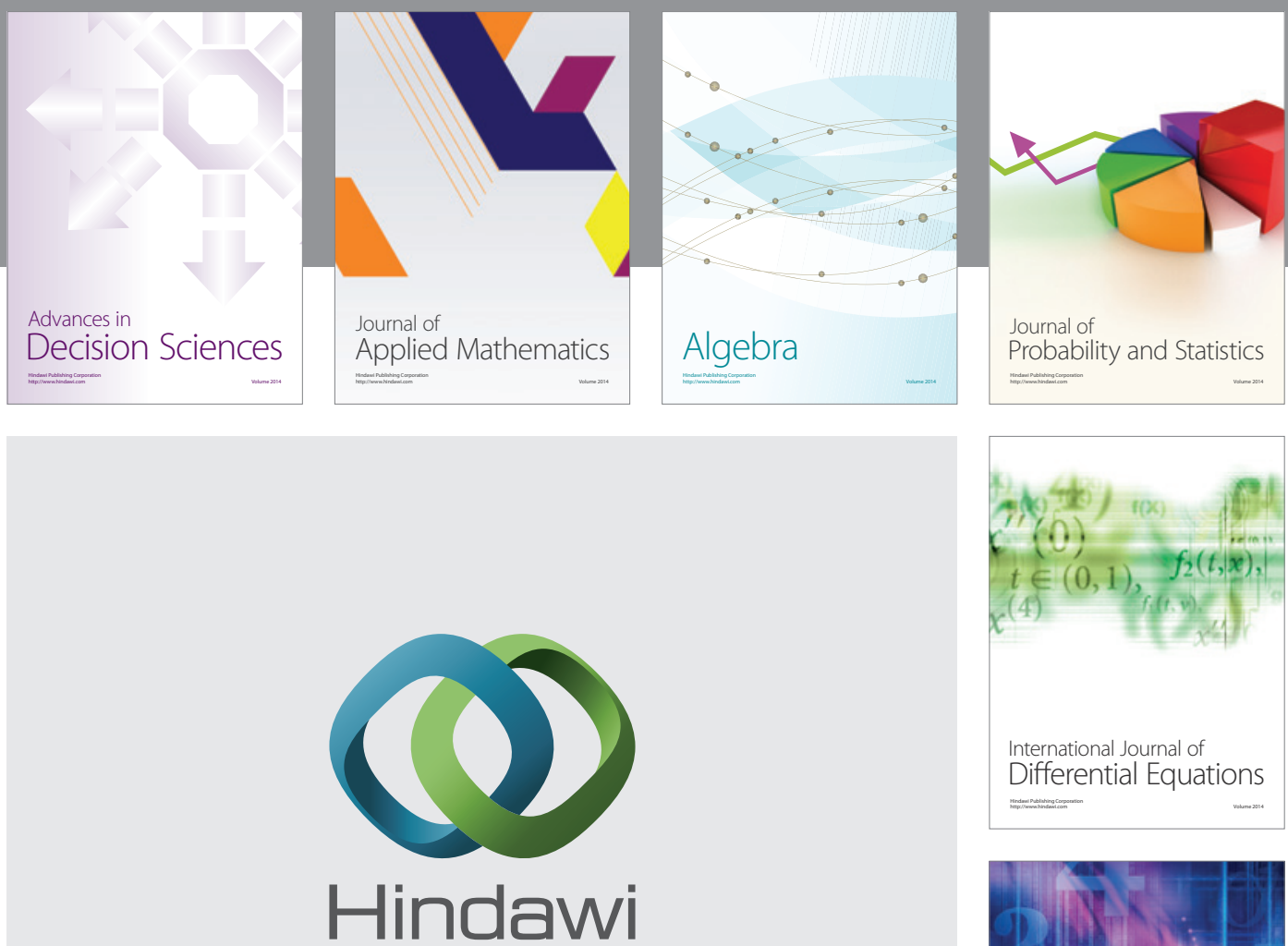

Submit your manuscripts at http://www.hindawi.com
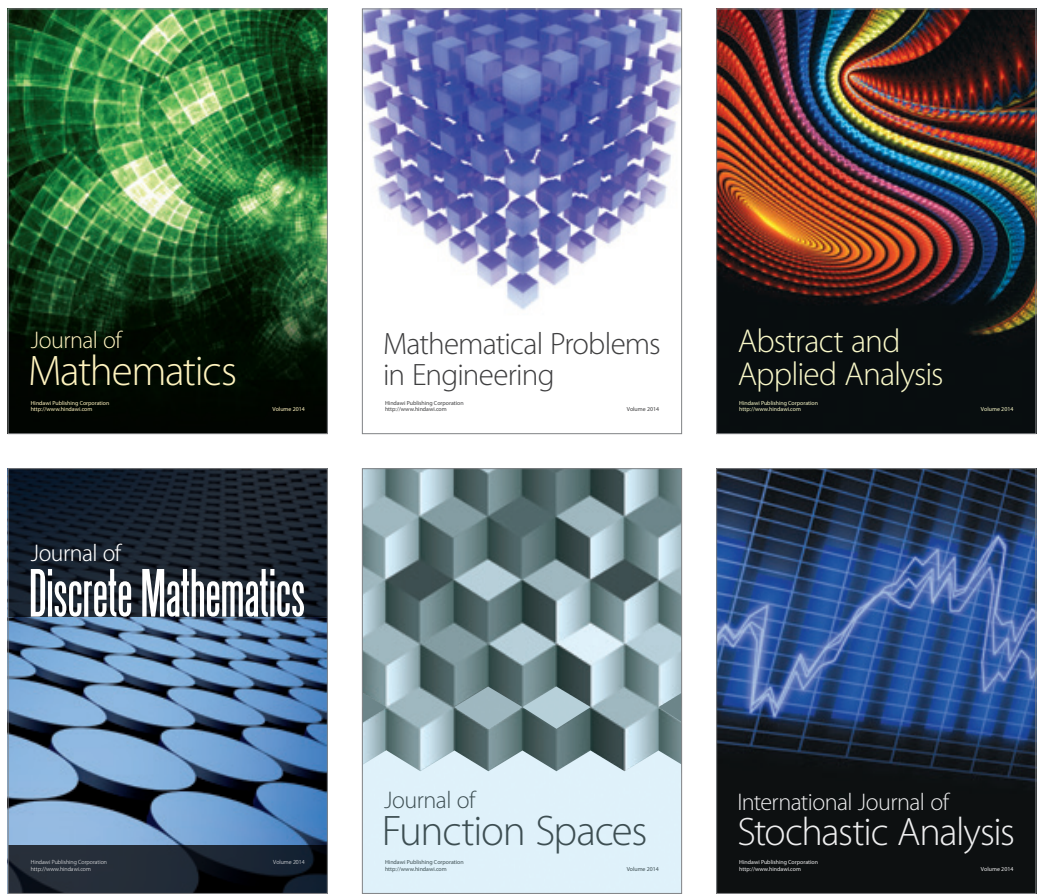

Journal of

Function Spaces

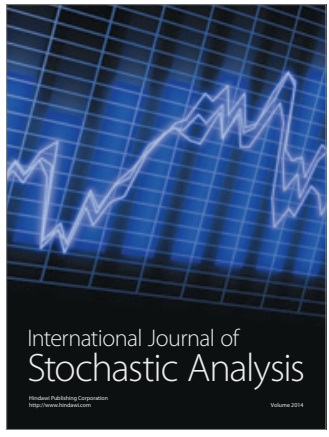

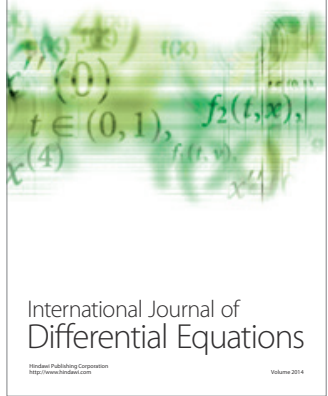
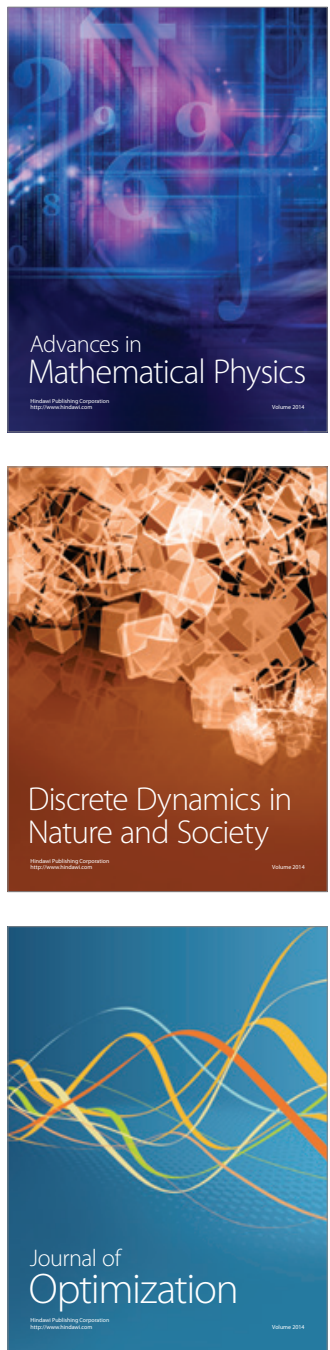